\title{
KRITIK DAN PEMECAHAN PENGGUNAAN KONSTRUKSI BETON COR PADA REKAYASA JALAN DALAM UPAYA MEMBANGUN KONSTRUKSI JALAN YANG BERKELANJUTAN
}

\section{Criticism and Troubleshooting Using Cast in Concrete Construction Engineering Road in Effort to Build Sustainable Road Construction}

\author{
Sarjono Puro ${ }^{1}$, Niken Atmiwyastuti ${ }^{2}$, Nina Restina ${ }^{3}$ \\ 1,2,3 Program Studi Teknik Sipil, Fakultas Teknik, Universitas Bung Karno \\ Alamat korespondensi :Jl.Kimia No.20 Jakarta 10114 \\ e-mail: ${ }^{1)}$ purosipit@yahoo.co.id , ${ }^{2}$ sofieniken@yahoo.co.id
}

\begin{abstract}
The policy using concrete casting construction on road engineering (including street) is often carried out by the goverment as the best way to improve the physical quality of the existing facilities. The decision in mainlyinfluenced by economiccalculation, despite the character of the cast concreteis well known for causing low waterabsorption rate, so that it could create water logging on the road during the rain. Therefore, it could also resultin losses due to damage, traffic congestion and the long term it can also degrades the economic value of the surrounding environment. In general, this paper is presenting critics on yhe use of cast concrete construction and the related materials, which is paving block constructionin order the meet the requirements of the sustainable construction standards.
\end{abstract}

Key words : cast concret ; road; sustainable construction; paving block

\begin{abstract}
Abstrak
Kebijakan menggunakan konstruksi beton pengecoran pada rekayasa jalan ( termasuk jalan ) sering dilakukan oleh pemerintah sebagai cara terbaik untuk meningkatkan kualitas fisik fasilitas yang ada . Keputusan dalam terutama dipengaruhi oleh perhitungan ekonomi, meskipun karakter beton cor terkenal karena menyebabkan tingkat penyerapan air rendah, sehingga bisa membuat genangan air di jalan selama hujan . Oleh karena itu , bisa juga resultin kerugian akibat kerusakan, kemacetan lalu lintas dan jangka panjang juga dapat menurunkan nilai ekonomi dari lingkungan sekitarnya. Secara umum, makalah ini menyajikan kritik atas penggunaan yhe konstruksi beton cor dan bahan terkait, yang paving block agar constructionin memenuhi persyaratan standar konstruksi yang berkelanjutan .
\end{abstract}

Kata kunci : beton cor ; jalan ; konstruksi berkelanjutan ; paving block

\section{PENDAHULUAN}

Tanah dan air adalah dua hal yang berhubungan erat dengan perkerasan. Selain memiliki manfaat positif yaitu meningkatkan daya dukung tanah terhadap aktivitas diatasnya, penggunaan perkerasan juga memiliki efek negatif terhadap tanah maupun air atau kedap air (Setya Mariana, 2008). Perlu diperhatikan bahwa lingkungan terbangun juga tetap akan berdampingan dengan lingkungan alam termasuk unsur-unsurnya seperti tanah dan air. Penggunaan perkerasan kedap air pada area yang cukup luas menyebabkan meningkatnya tingkat dan volume aliran air pada permukaan tanah. Hal ini disebabkan karena penggunaan perkerasan akan menciptakan permukaan yang tidak bisa ditembus oleh air. Sebagian besar perbaikan jalan yang dilakukan Pemerintah pada saat ini kita ketahui banyak sekali menggunakan konstruksi beton cor. Keputusan tersebut lebih banyak dilatarbelakangi pertimbangan ekonomi semata, padahal diketahui bahwa karakter konstruksi beton cor menyebabkan tingkat daya serap air rendah, sehingga bila tidak memperhatikan sistem drainasenya, maka akan menimbulkan genangan air yang pada akhirnya timbul kerusakan struktur yang memerlukan tidak sedikit waktu dan nilai biaya perbaikannya (M.Syahdanulirwan, 2013). Masalah tersebut 
seringkali kita jumpai khususnya pada jalan lingkungan. Pada Gambar 1 berikut ini menunjukkan jalan lingkungan yang tergenang air akibat drainase jalan yang tertutup.
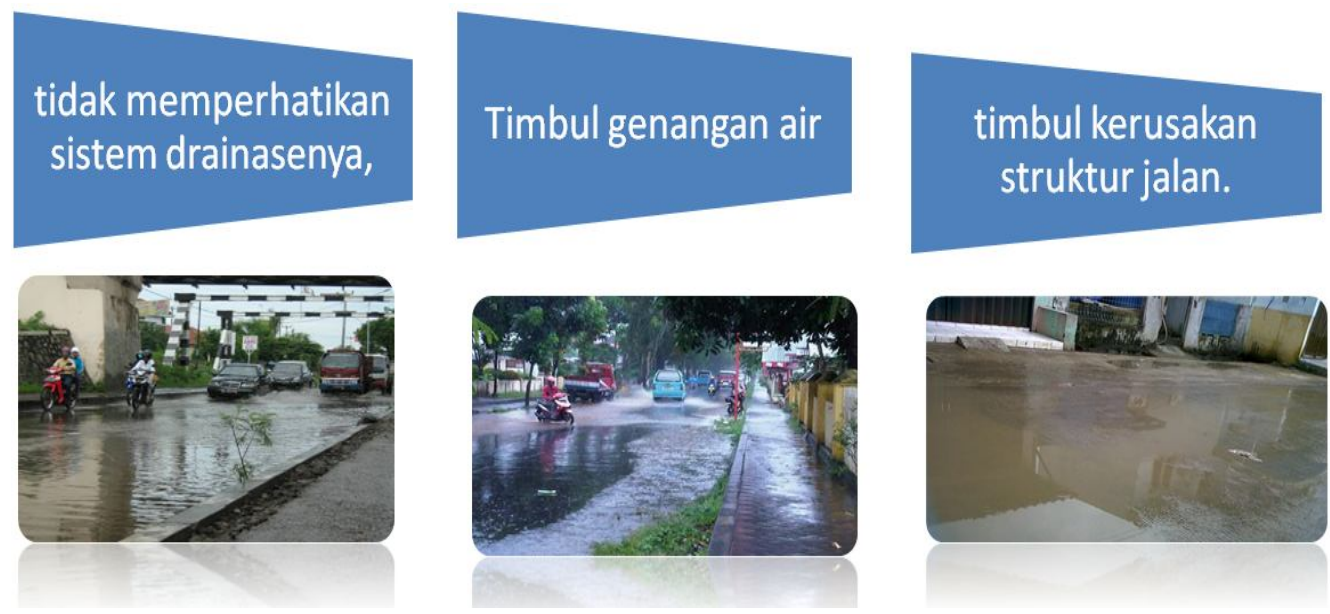

Gambar 1. Sistem Drainase Yang Buruk

Dampak pada konstruksi jalan yaitu perubahan bentuk lapisan permukaan jalan berupa lubang (potholes), bergelombang (rutting), retak-retak dan pelepasan butiran (ravelling) serta gerusan tepi yang menyebabkan kinerja jalan menjadi menurun. Kasus-kasus kerusakan jalan lingkungan ditunjukkan pada Gambar 2.

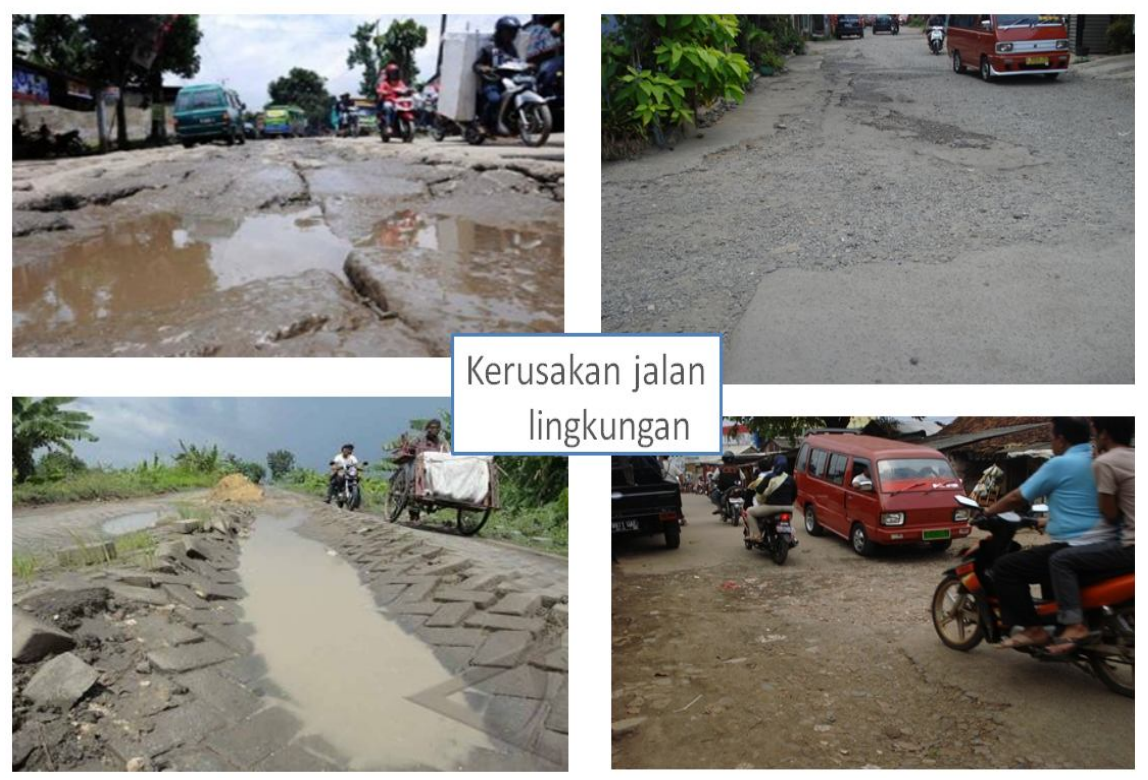

Gambar 2. Kerusakan Jalan Lingkungan

Pentingnya mengetahui penyebab kerusakan dan cara pemeliharaan jalan tersebut, agar tercipta jalan yang aman,nyaman dan memberikan manfaat yang signifikan bagi kesinambungan dan keberlangsungan hidup masyarakat luas. Meyikapi hal tersebut bukan tidak mungkin struktur jalan beralih pada konstruksi paving block sebagai alternatif dalam rekayasa jalan yang masih jarang penggunaannya. Umumnya paving block digunakan untuk perkerasan jalan, pedestrian dan trotoar. Penggunaan paving block diharapkan dapat memenuhi syarat konstruksi yang berkelanjutan. Dalam upaya memenuhi konstruksi jalan yang berkelanjutan maka perlu pemahaman Potensi (jumlah, jenis bahan, fungsi lahan, kondisi lingkungan), proses produksi dan transportasi yang ramah lingkungan (low energi, low emisi, low waste), aman terhadap kesehatan (radiasi, toxid), Memenuhi persyaratan teknis dan lingkungan serta low /free maintenance. Paradigma pembangunan berkelanjutan ditunjukkan pada Gambar 3. Kemudahan dalam pemasangan, perawatan yang 
relatif murah serta memenuhi aspek keindahan mengakibatkan paving block lebih banyak disukai (Fauna Adibroto). Penggunaan paving block sangatlah mendukung go green yang telah dikumandangkan secara nasional/internasional, karena daya serap air melalui pemasangan paving block dapat menjaga keseimbangan air tanah. Penggunaan perkerasan memang diperlukan untuk mendukung fungsi suatu lingkungan terbangun dalam mendukung kegiatan manusia yang akan diakomodasi oleh lingkungan terbangun tersebut secara terus-menerus. Bagaimana penggunaan paving block sebagai material yang ramah lingkungan dan bagaimana untuk mengetahui sistem konstruksi berkelanjutan dalam rekayasa jalan lingkungan. Kebutuhan infrastruktur jalan sebagai penghubung kawasan hunian sebagai pemenuhan akan meningkatnya mobilitas antartempat dan kebutuhan akan moda transportasi (Altim Setiawan, 2006)

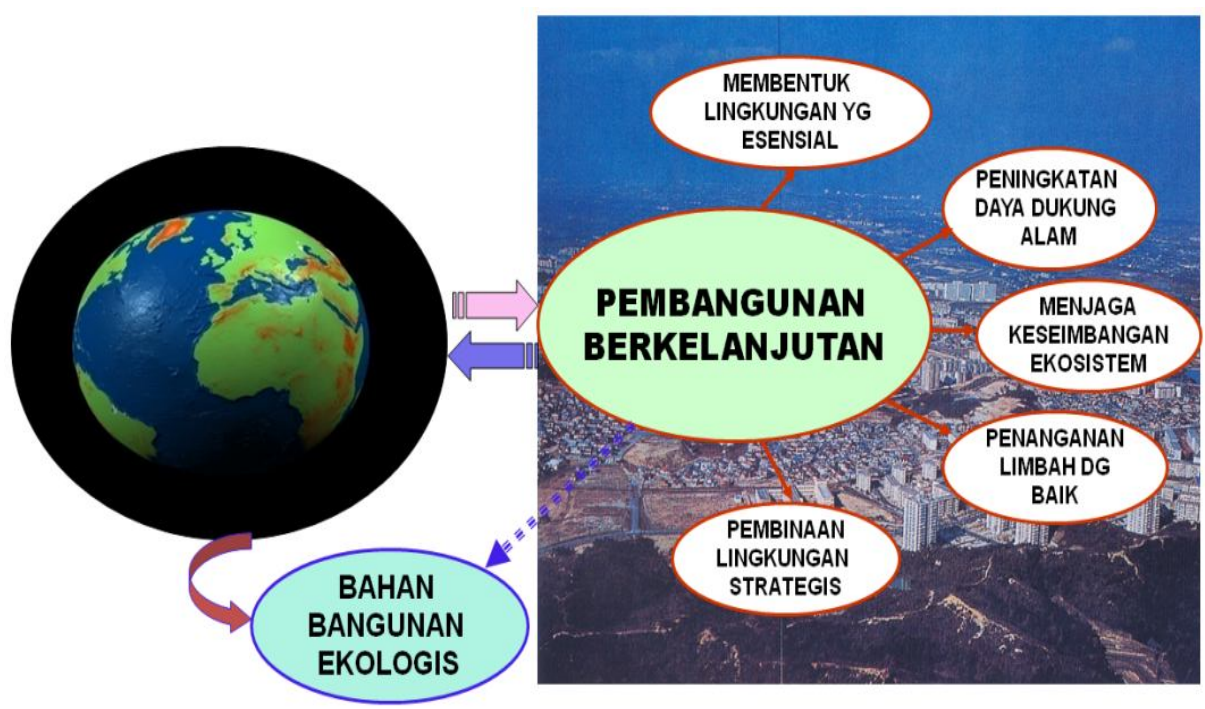

Gambar 3. Paradigma Pembangunan Berkelanjutan

Adapun tujuan dan manfaat dalam penelitian ini adalah

- Untuk mengetahui sejauh mana penggunaan paving block sebagai konstruksi jalan lingkungan yang ramah lingkungan

- Untuk mengetahui sistem konstruksi berkelanjutan dalam rekayasa jalan lingkungan

- Memberikan sumbangan pengetahuan pada kajian material ramah lingkungan

- Memberikan sumbangan praktis pelaksanaan rekayasa jalan lingkungan

\section{METODE PENELITIAN}

Metode penelitian ditunjukkan pada bagan alir dalam paper ini seperti yang ditunjukkan pada Gambar 4.

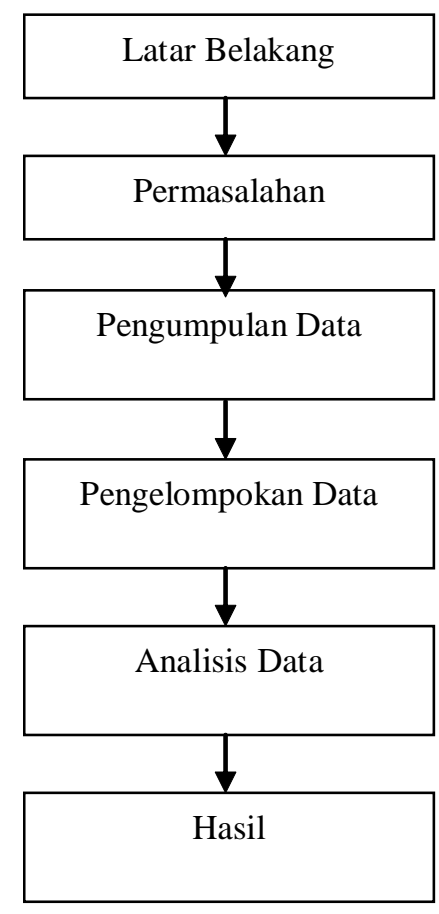

Gambar 4. Bagan Alir Penelitian 


\section{HASIL DAN PEMBAHASAN}

\section{Gambaran umum penelitian}

Flexible pavement /perkerasan lentur/aspal (Gambar 5) adalah perkerasan lentur dengan bahan pengikat aspal yang sering disebut campuran aspal panas atau hot mix. Perkerasan lentur dengan bahan pengikat aspal yang sering disebut campuran aspal panas atau hot mix. Pemakaian tipe perkerasan lentur tersebut semakin meningkat seiring dengan meningkatnya pengembangan suatu daerah. Untuk memenuhi kebutuhan tersebut dilakukan (impor dari luar negeri seperti aspal Shell, ESSO 2000 dan lainlain). Komponen aspal memberikan sumbangan sebesar $60 \%$ dari biaya total hot mix.

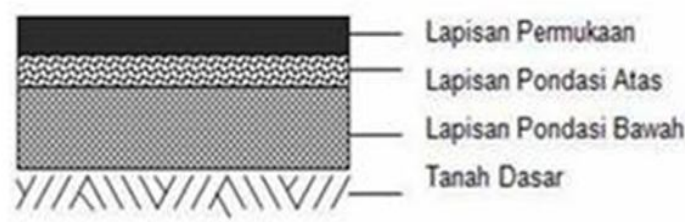

Perkerasan Lentur (Plexibel Pavment)
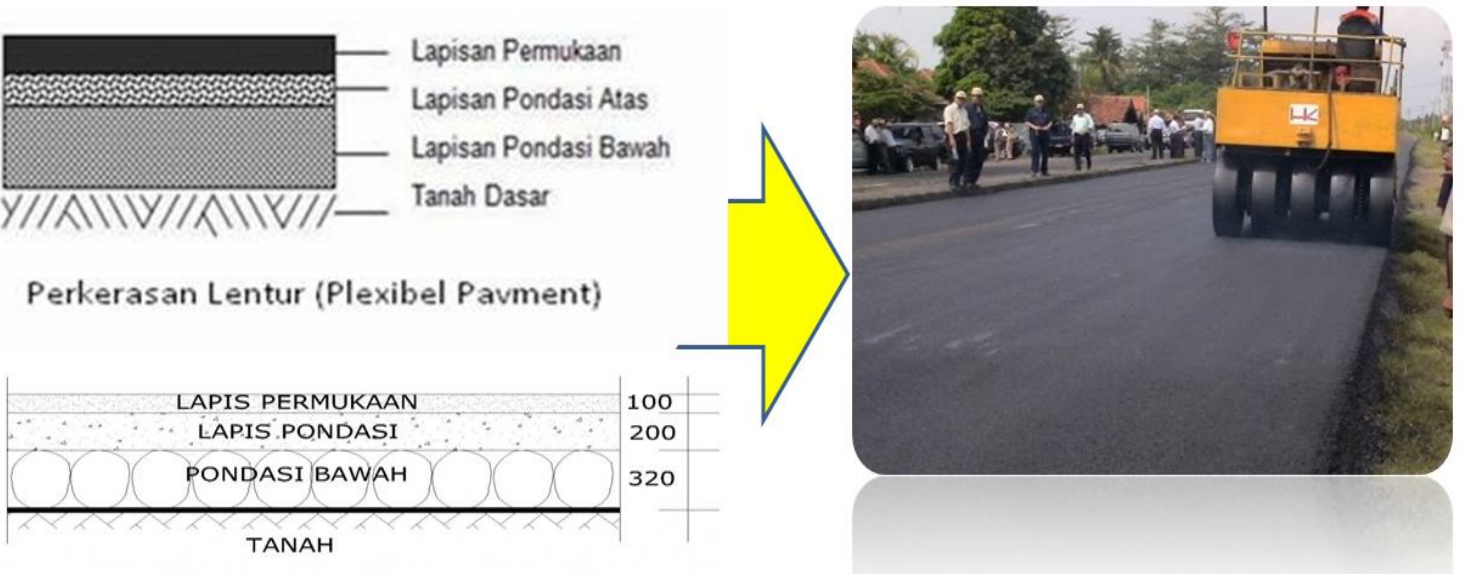

Gambar 5. Flexible pavement /perkerasan lentur/aspal
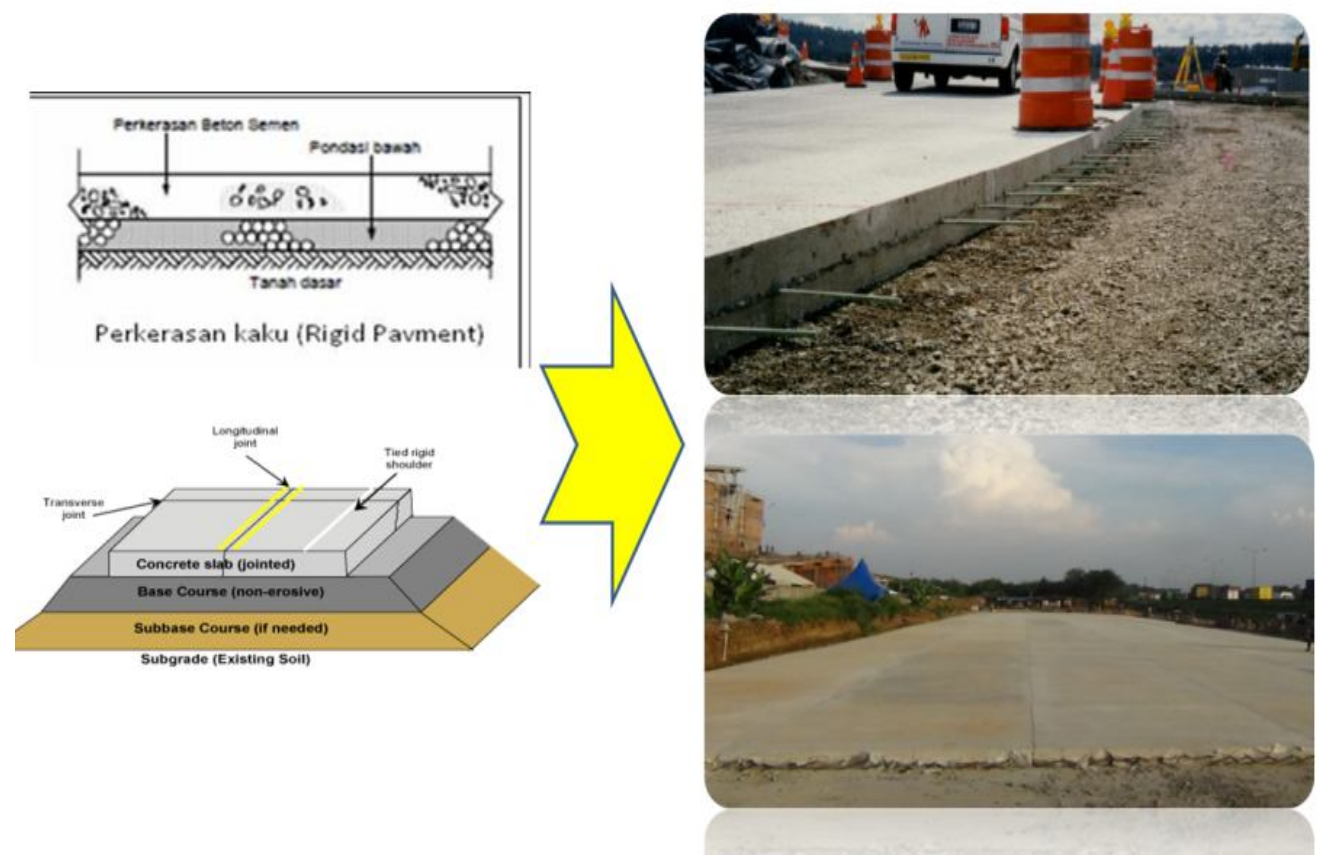

Gambar 6. Rigid pavement/ perkerasan kaku/ beton

Rigid pavement (perkerasan kaku/Beton (Gambar 6) adalah Perkerasan jalan beton semen atau secara umum disebut perkerasan kaku, terdiri atas plat (slab) beton semen sebagai lapis pondasi dan lapis pondasi bawah (bisa juga tidak ada) di atas tanah dasar. Dalam konstruksi perkerasan kaku, plat beton sering disebut sebagai lapis pondasi karena dimungkinkan masih adanya lapisan aspal beton di atasnya yang berfungsi sebagai lapis permukaan.Perkerasan beton yang kaku dan memiliki modulus elastisitas yang tinggi, akan mendistribusikan beban ke bidang tanah dasar yang cukup luas sehingga bagian terbesar dari kapasitas struktur perkerasan diperoleh dari plat beton sendiri. Hal ini berbeda dengan perkerasan lentur dimana kekuatan perkerasan diperoleh dari tebal lapis 
pondasi bawah, lapis pondasi dan lapis permukaan. Karena yang paling penting adalah mengetahui kapasitas struktur yang menanggung beban, maka faktor yang paling diperhatikan dalam perencanaan tebal perkerasan beton semen adalah kekuatan beton itu sendiri. Adanya beragam kekuatan dari tanah dasar dan atau pondasi hanya berpengaruh kecil terhadap kapasitas struktural perkerasannya. Lapis pondasi bawah jika digunakan di bawah plat beton karena beberapa pertimbangan, yaitu antara lain untuk menghindari terjadinya pumping, kendali terhadap sistem drainasi, kendali terhadap kembangsusut yang terjadi pada tanah dasar dan untuk menyediakan lantai kerja (working platform) untuk pekerjaan konstruksi.
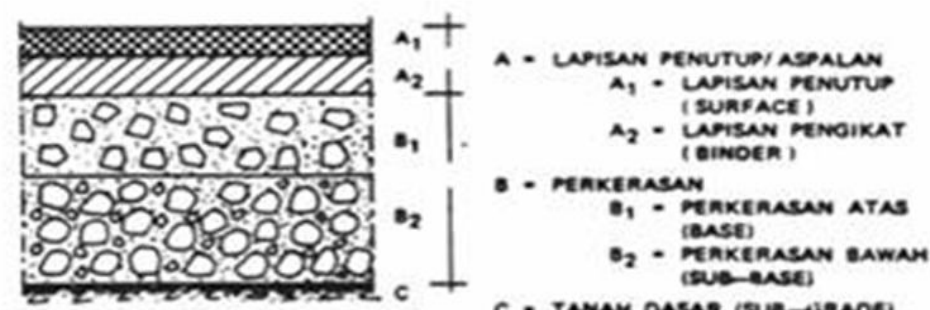

c tavar onsar isua-unaoes

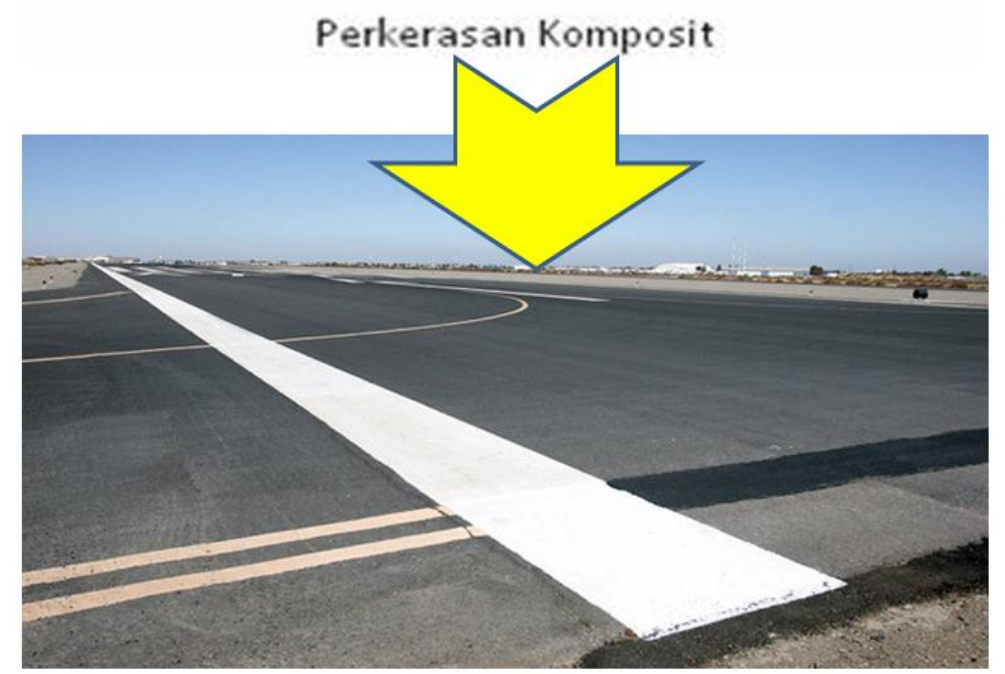

Gambar 7.Perkerasan Komposit

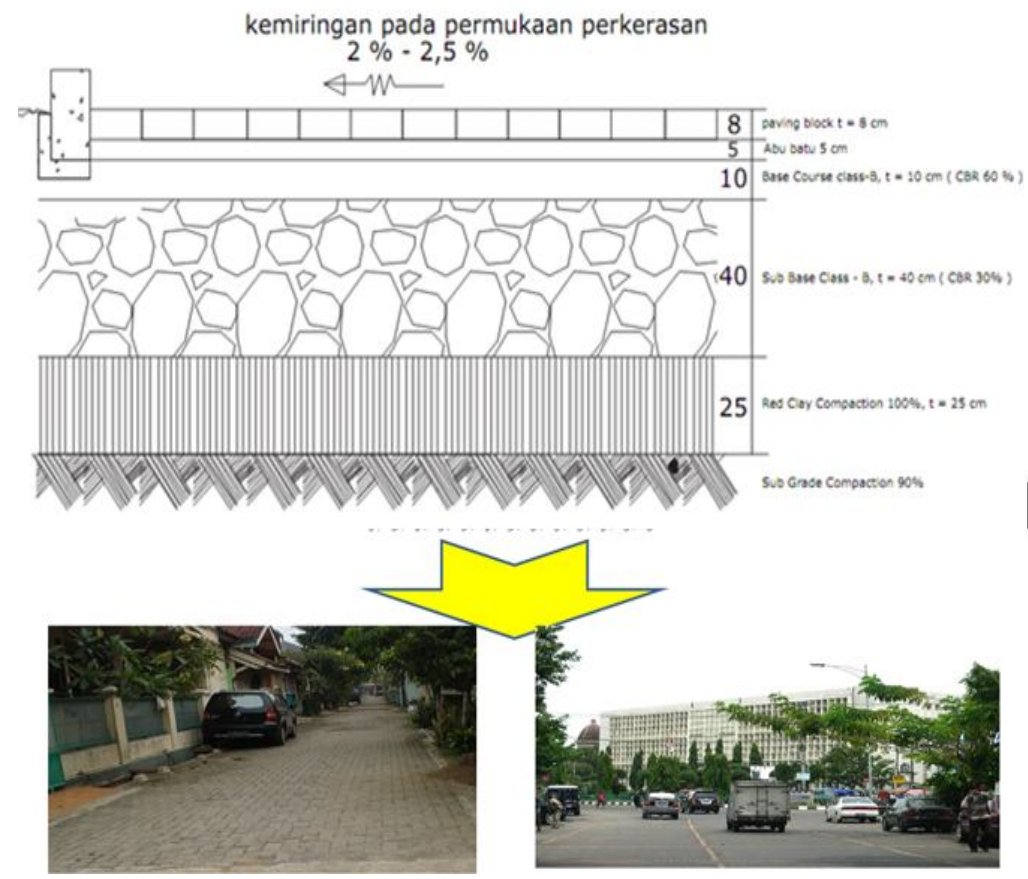

Gambar 8. Block pavement /perkerasan menggunakan paving block 


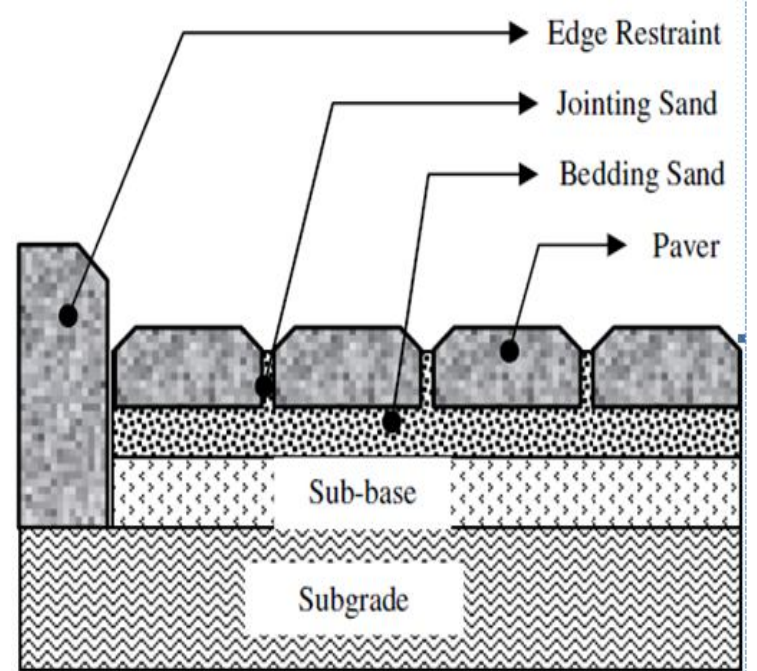

Gambar 9. Struktur perkerasan paving block (Rachmat Mudiyono, 2007)

\section{Perkerasan Komposit (Gambar 7) :} Perkerasan kaku dengan plat beton semen sebagai lapis popndasi dan aspal beton sebagai lapis permukaan. Perkerasan kaku ini sering digunakan sebagai runway lapangan terbang.

Block pavement /perkerasan menggunakan paving block (Gambar 8) : Jenis perkerasan jalan lainnya yaitu paving block, adalah bahan bangunan yang terdiri dari campuran semen, pasir, air, sehingga karakteristiknya hampir mendekati mortar, sehingga bahan perkerasan Paving yang terbuat dari campuran pasir dan semen ditambah atau tanpa campuran lainnya ( abu batu atau lainnya ). Paving block atau blok beton terkunci menurut SII.0819-88 adalah suatu komposisi bahan bangunan yang terbuat dari campuran semen portland atau bahan

perekat hidrolis lainnya, air dan agregat dengan atau tanpa bahan tambahan lainnya yang tidak mengurangi mutu beton tersebut. Sedangkan menurut SK SNI T-04-1990-F, paving block adalah segmen-segmen kecil yang terbuat dari beton dengan bentuk segi empat atau segi banyak yang dipasang sedemikian rupa sehingga saling mengunci (Dudung Kumara, 1992; Akmaluddin dkk. 1998). Struktur perkerasan paving block di bawah permukaan mirip dengan permukaan perkerasana dengan aspal seperti yang ditunjukkan pada Gambar 9.

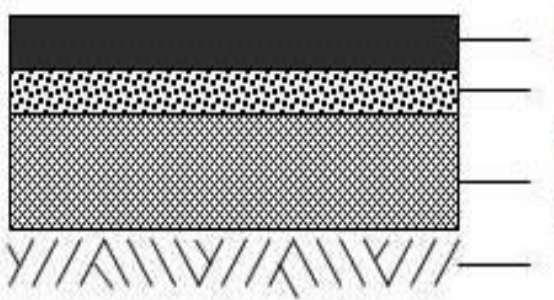

Lapisan Permukaan Lapisan Pondasi Atas Lapisan Pondasi Bawah Tanah Dasar

\section{Gambar 10. jenis lapisan perkerasan}

Pada umumnya, perkerasan jalan terdiri dari beberapa jenis lapisan perkerasan (lihat Gambar 10) yang tersusun dari bawah keatas, sebagai berikut :

- Lapisan tanah dasar (sub grade)

- Lapisan pondasi bawah (subbase course)

- Lapisan pondasi atas (base course)

- Lapisan permukaan / penutup (surface course

\section{Analisis / Solusi Pemecahan}

Tabel 1 . Karakteristik konstruksi beton

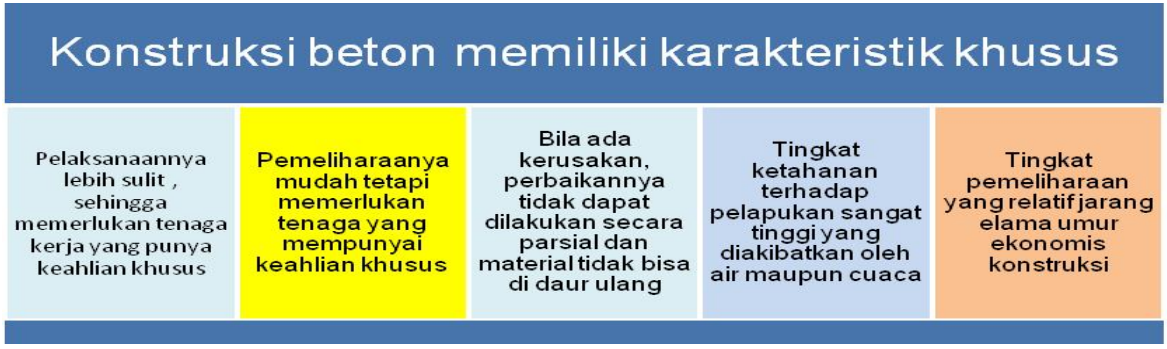

Tabel 2. Karakteristik Kontruksi paving block

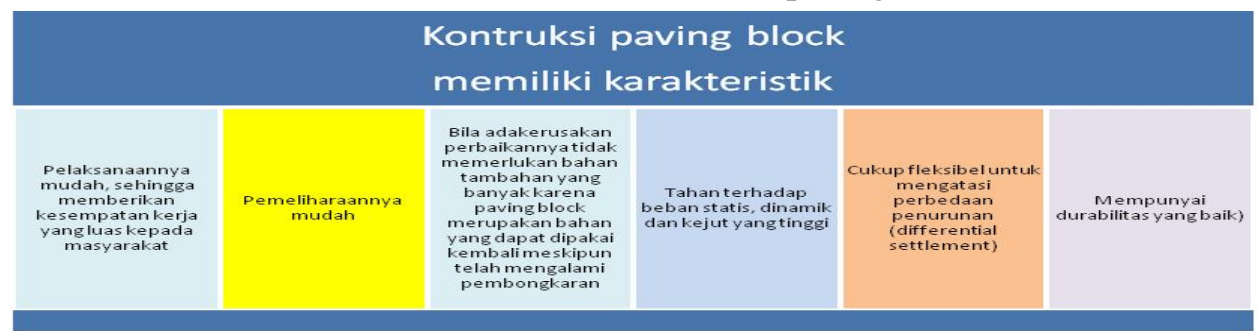


Tabel 3. Sifat fisk paving block atau disebut juga batu cetak

\begin{tabular}{cccccc}
\hline \multirow{2}{*}{ Mutu } & \multicolumn{2}{c}{ Kekuatan (Mpa) } & \multicolumn{2}{c}{ Katahanan Aus (mm/menit) } & Persentase Kadar air \\
& Rata-rata & Terendah & Rata-rata & Terendah & rata-rata (\%) \\
\hline I & 40 & 34,0 & 0,090 & 0,103 & 3 \\
II & 30 & 25,5 & 0,130 & 1,149 & 5 \\
III & 20 & 17,0 & 0,160 & 0,134 & 7 \\
\hline
\end{tabular}

Sumber : SK SNI-04-1989-F

Pemasangan paving block dapat ., bentuk, mutu dan tebal dapat dilihat pada Tabel 4

Tabel 4. Penggunan paving block

\begin{tabular}{clccc}
\hline \multirow{2}{*}{ No } & \multicolumn{1}{c}{ Penggunaan } & \multicolumn{3}{c}{ Kombinasi } \\
\cline { 3 - 5 } & & Kelas & Tebal $(\mathrm{mm})$ & Pola \\
\hline 1 & Trotoar dan Pertamanan & II & 60 & SB, AT, TI \\
2 & Tempat parkir dan Garasi & II & 60 & SB, AT, TI \\
3 & Jalan Lingkungan & I/II & $60 / 80$ & TI \\
4 & Terminal Bus & I & 80 & TI \\
5 & Container Yard, Taxy way & I & 100 & TI \\
\hline
\end{tabular}

Sumber : SK SNI T-04-1990-F

Catatan pola $: \mathrm{SB}=$ Susunan Bata, $\mathrm{AT}=$ Anyaman Tikar, $\mathrm{TI}=$ Tulang Ikan

\section{Klasifikasi Paving block}

Menurut SK SNI T-04-1990-F, klasifikasi paving block ini berdasarkan atas bentuk, tebal, kekuatan, dan warna. Klasifikasi berdasarkan bentuk Paving block secara garis besar terbagi atas dua macam, yaitu:

- $\quad$ Paving block segi empat

- $\quad$ aving block segi banyak

Pemilihan bentuk dan ketebalan dalam pemakaian harus disesuaikan dengan rencana penggunaanya, dalam hal ini juga harus diperhatikan kuat tekan paving block tersebut

\section{Klasifikasi berdasarkan Ketebalan}

Ketebalan paving block terbagi menjadi tiga macam, yaitu :

- $\quad$ Paving block dengan mutu beton I dengan nilai f'c3 4 - $40 \mathrm{Mpa}$

- Paving block dengan mutu beton I I dengan nilai f'c 25,5 - $30 \mathrm{Mpa}$

- $\quad$ Paving block dengan mutu beton IIIdengan nilai f'c 17-20Mpa

\section{Klasifikasi berdasarkan warna}

Abu-abu, hitam, dan merah, Paving bock yang berwarna, kecuali untuk menambah keindahan juga dapat digunakan untuk memberi batas seperti tempat parkir, tali air, dan lain sebagainya.

\section{Kuat Tekan}

Pengujian kuat tekan pada beton dilakukan dengan menekan benda uji silinder $150 \mathrm{~mm}$ x 300 mm pada standar ACI, SNI dan kubus $150 \mathrm{~mm} x$ $150 \mathrm{~mm}$ pada standar Inggris. Kuat hancur paving block dipengaruhi oleh sejumlah faktor, yaitu :

- Jenis dan kualitasnya, mempengaruhi kekuatan rata-rata dan kuat tekan bebas beton

- Jenis dan lekuku-lekuk bidang permukaan sgregat

- $\quad$ Efisiensi dari perawatan (curung), kehilangan kekuatan sampai sekitar 40\% dapat terjadi bila pengerinan diadakan sebelum waktunya

- 4. Suhu, pada umumnya kecepatan pengerasan beton meningkat dengan bertambahnya suhu. Pada titik beku kuat tekan akan tetap untuk waktu yang sama.

Berikut adalah gambaran perbandingan pekerjaan konstruksi dan kondisi jalan lingkungan dengan menggunakan konstruksi paving block dan cor. Perbaikan pada struktur perkerasan di bawah paving block. Perbaikan mudah dilakukan, sehingga menghemat biaya, waktu dan tenaga dan dengan melibatkan tenaga kerja lokal seperti pada Gambar 12 dan Gambar 13. Paving block juga dapat betahan cukup lama seperti di Perumahan Bukit Nusa Indah Ciputat sudah berumur lebih dari 20 tahun yang ditunjukkan pada Gambar 12, dengan biaya perawatan sangat murah. 

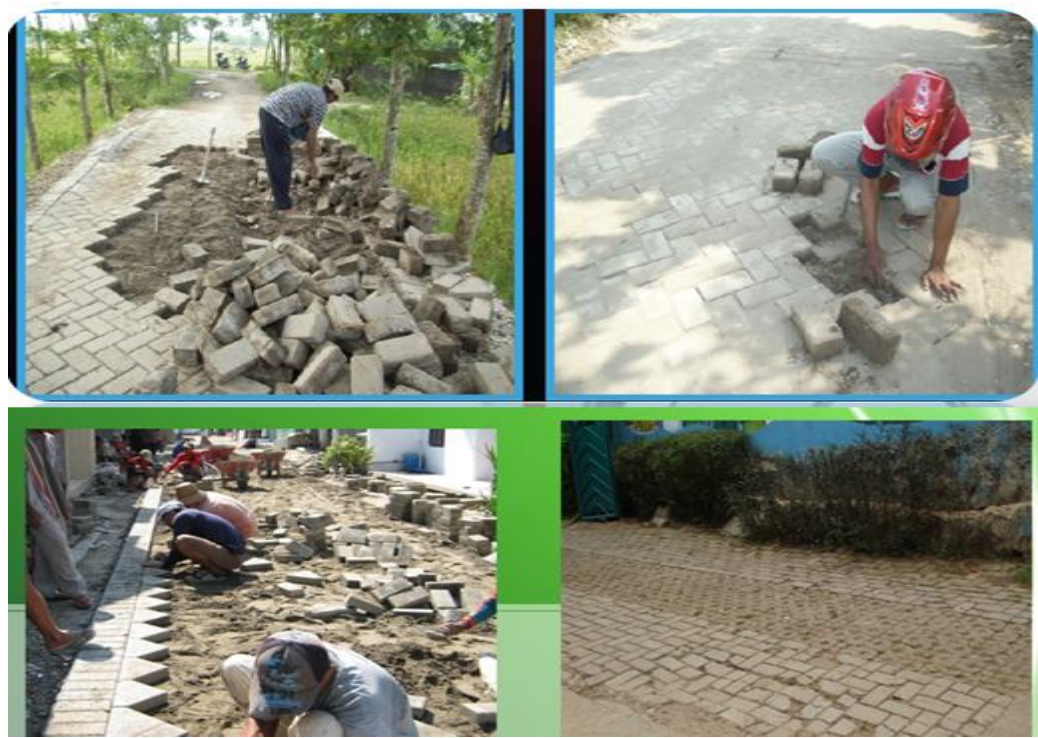

Gambar 11. Konstruksi Batu Cetak Halaman (Paving Block)

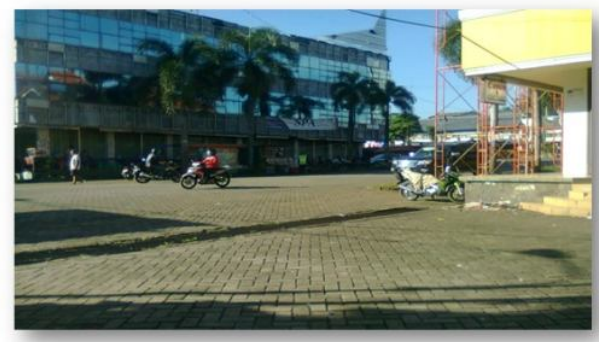

Ruko Griya - Perum Griya

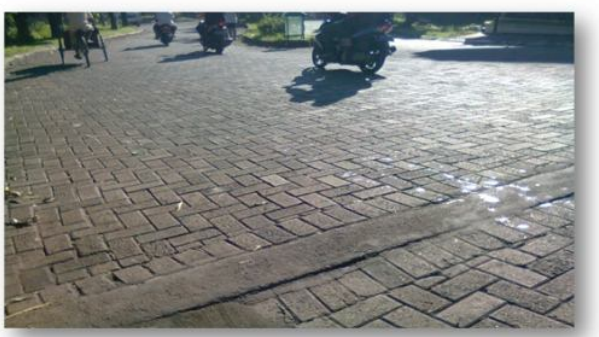

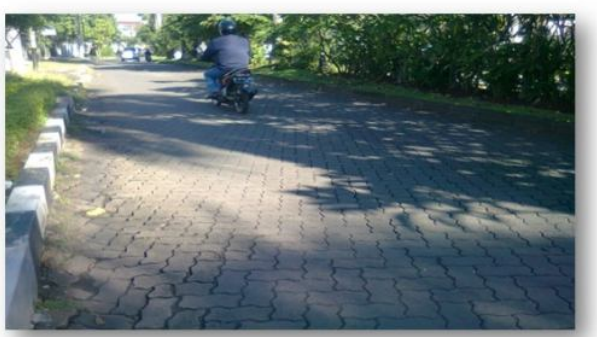

Bukit Nusa Indah - Ciputat (tahun 90an)

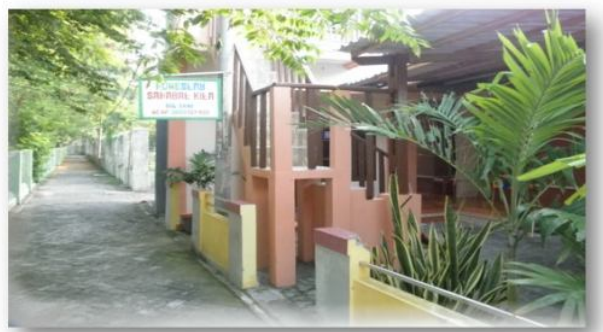

Gambar 12. Kondisi Perkerasan Paving Block
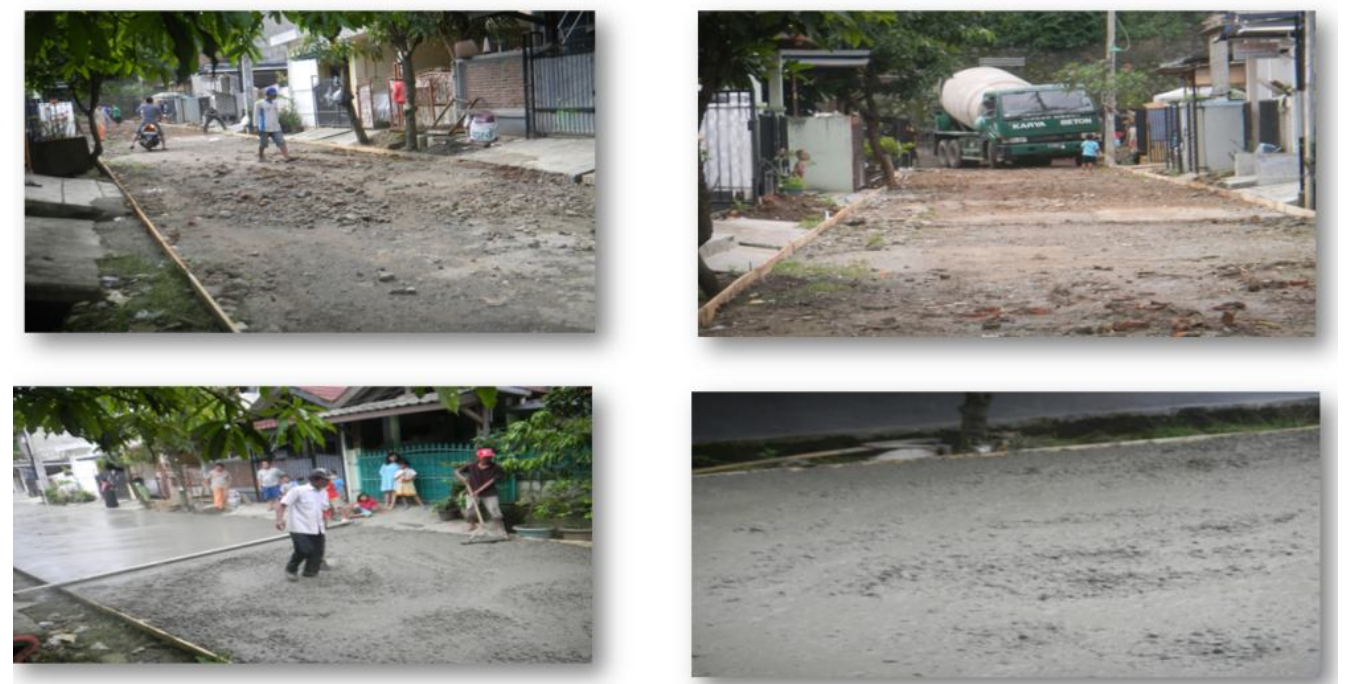

Gambar 13. Konstruksi Jalan Lingkungan Dengan Cor 

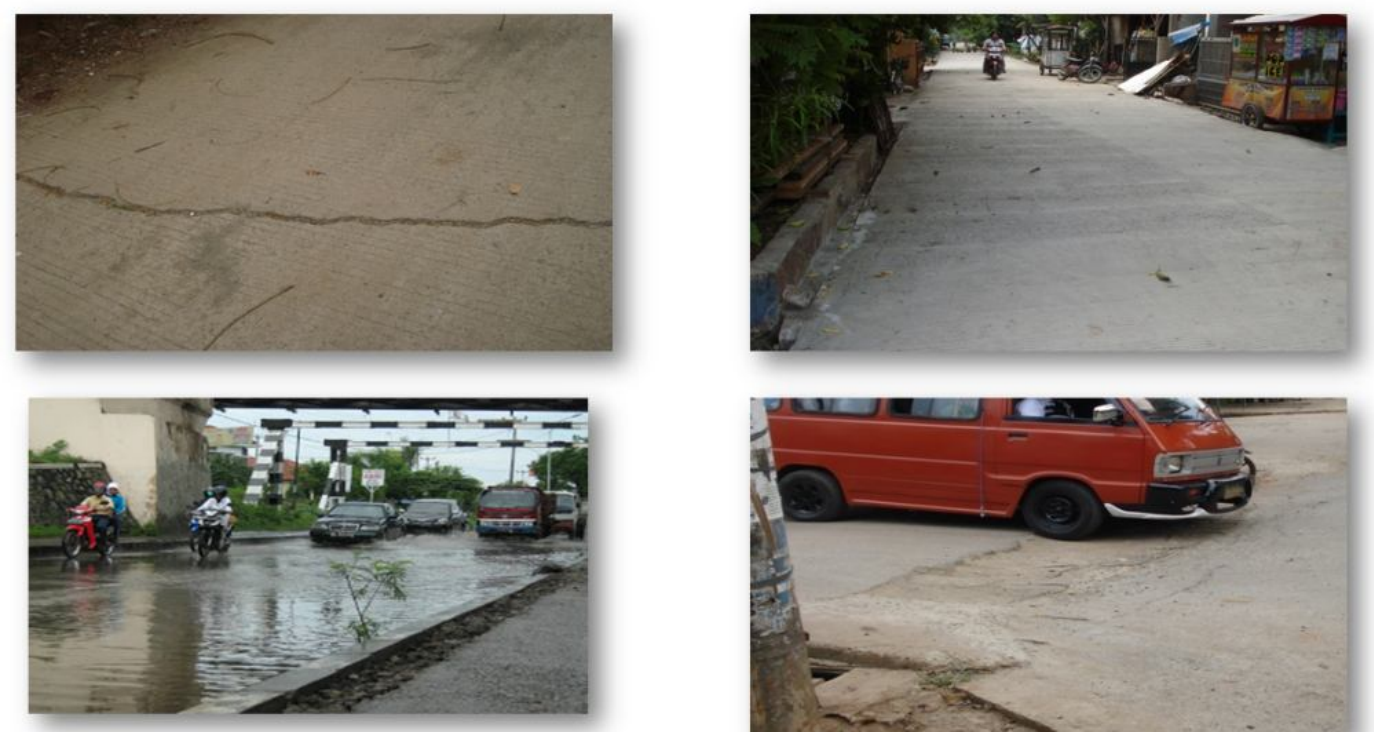

Gambar 14. Kondisi Jalan Lingkungan Dengan Cor

Pada pekerjaan perkerasan cor harus menggunakan alat bantu khusus seperti mobil pengangkut beton Pada pelaksanaan pekerjaan diperlukan pengawasan yang sangat ketat agar hasilnya sesuai dengan spesifikasi dan tidak mengalami kegagal seperti yang ditunujukkan pada Gambar 13 dan Gambar 14.

Perbandingan kontruksi beton cor dengan konstruksi paving block dapat dilihat pada tabel 5 :

Tabel 5. Perbandingan kontruksi beton cor dengan konstruksi paving block

\begin{tabular}{l}
$\begin{array}{c}\text { Konstruksi Beton Cor } \\
\text { (Rigid Pavement) }\end{array}$ \\
\hline 1. Desain sederhana, namun pada bagian \\
sambungan perlu perhitungan lebih teliti. \\
Kebanyakan digunakan pada jalan jalan dengan \\
volume lalu lintas tinggi, serta pada perkerasan \\
lapangan terbang
\end{tabular}

2. Rongg Udara di dalam beton tidak dapat mengurangi tegangan yang timbul akibat perubahan volume beton.Pada umumnya diperlukan sambungan untuk mengurangi tegangan akibat perubahan temperatur

3. Umur rencana dapat mencapai 15 - 40 tahun

4. Jika terjadi kerusakan, maka kerusakan tersebut cepat dan dalam waktu singkat dapat meluas

5. Pada umumnya biaya awal konstruksi tinggi (cukup mahal) karena memerlukan perlatan berat

6. Pelaksanaan cukup rumit karena pengerjaannya memerlukan keahlian khusus serta tidak dapat langsung dibuka untuk lalu lintas

7. Pemeliharaan Perbaikan cukup rumit karena harus membongkar satu segmen bagian yang rusak, material tidak dapat dipasang kembali lagi

8. Material beton diproduksi secara pabrikasi, dan proses pengerjaannya harus sesuai prosedur untuk mendapatkan hasil sesuai spesifikasi

\section{Konstruksi Batu Cetak Halaman (Paving Block)}

1. Perancangan sederhana dan hanya dapat digunakan untuk tingkat volume lalu lintas rendah berdasarkan klasifikasi fungsi jalan raya, seperti trotoar dan pertamanan, tempat parkir, jalan lingkungan, terminal bis.

2. Rongga udara di dalam paving block dapat menyerap air pada lapisan dibawahnya, sehingga dapat membantu sistem drainase yang baik

3. Umur rencana relatif pendek $<5$ tahun.

4. Kerusakan tidak merambat ke bagian konstruksi yang lain, kecuali jika pembebanan lalu lintasnya sudah sangat tinggi

5. Pada umumnya biaya awal konstruksi relatif rendah.

6. Pelaksanaan relatif sederhana karena dapat dilakukan secara masala oleh masyarakat setempat serta dapat dibuka langsung ntuk lalu lintas

7. Pemeliharaan Perbaikana mudah dan material dapat dipasang kembali setelah dibongkar dan memperhatikan aspek berkelanjutan

8. Material paving dapat diproduksi baik secara mekanis, cara semi mekanis dan secara manual dengan cetak tangan 


\section{KESIMPULAN DAN SARAN}

Kesimpulan

Dari hasil pembahasan dapat disimpulkan bahwa:

- Dengan menggunakan konstruksi paving block dapat digunakan sebagai alternatif perbaikan jalan selain konstruksi beton cor karena materialnya yang ramah lingkungan.

- Konstruksi paving block dengan strukturnya yang berpori dapat membantu menyerap air dan mengalirkan ke saluran drainase dengan baik

- Konstruksi paving block selain biaya awal sampai dengan pemeliharaannya murah juga memberikan kesempatan kerja yang luas bagi masyarakat dalam pengerjaannya.

\section{Saran}

- Perlunya penelitian atau kajian lanjutan tentang umur dan kekuatan jalan lingkungan yang menggunakan paving block .

- $\quad$ Studi komparasi antara jalan lingkungan yang menggunakan paving block dan beton cor dari segi nilai ekonomis

\section{DAFTAR PUSTAKA}

Anthony N.S. Beaty, (1997). Environmentally Sustainable Interlocking Block Paveent, the Roads/Transportation and the Environment Session of the XIII ${ }^{\text {th }}$. IRF World Meeting

Archondo-CALLAO \& Rodrigo S,( 2009). Economic Evaluation Of Paving Rural Roads With Adoqines, $9^{\text {th }}$. International Conference on Concrete Block Paving. Buenos Aires, Argentina, Argentinean Concrete Block Association (AABH) - Argentinean Portland Cement Institute (ICPA) Small Element Paving Technologists (SEPT)

Eddy Djunaidi, (2013). Implementasi Pembangunan Jalan Lingkungan Masyarakat Dalam Peningkatan Pelayanan Publik Pada Dinas Cipta Karya Dan Tata Kota Samarinda, eJournal Administrative Reform

Iskandar Muda Purwaamijaya, (2013). Model Perubahan Lingkungan Di Koridor Jalan Untuk
Mewujudkan Pembangunan Berkelanjutan, Konferensi Nasional Teknik Sipil 7 (KoNTekS 7)Universitas Sebelas Maret (UNS) - Surakarta

Mariana, Setya, (2008), Penggunaan perkerasan yang berfungsi ekologis, Tesis Magister, Fakultas Teknik Arsitektur, Departemen Arsitektur, Universitas Indonesia, Depok

Peraturan Pemerintah RI Nomor 34 Tahun (2006) tentang Jalan

Rachmat Mudiyono et al, (2007). Performance of Concrete Block Pavement On Sloped Road Section, International Journal of Pavement; 6 (1-2-3): 136-145.

Sebayang.S, Diana I.W, dan Purba A, (2011), Perbandingan mutu paving block produksi manual dengan produksi masinal, Jurnal rekayasa Vol.15 No.2.

Undang -Undang RI Nomor 38 Tahun (2004) tentang Jalan

Wega Syamdermawan, (2012). Pengaruh Ruang terbuka Hijau Terhadap Kualitas Lingkungan Pada Perumahan, Teknologi Dan kejuruan, Vol 35 No 1. 